\title{
Medicaid Managed Care Reform: Making it Work for Children
}

Julie A. Helmt

Juli A. Helm will complete the Masti? of

Publit Administration

promrant at The

Gombe Washingtom

Uniwewity in May

loog) witl at

ionicuthation in

Heithis Seritis

Monglement owd

Polloy Jille is

willeth at

Comlintisional tilloni

at Litat Motm.

Compan, whelet

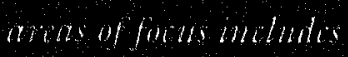

benlth and owd

chatromit commotio.

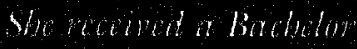

of Ants in Eublwh and

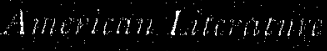

fom Non hork

Cunbosty m logs

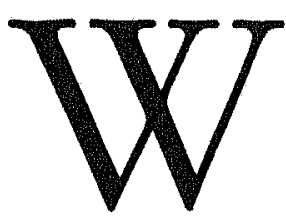

hen President Lyndon Johnson signed legislation establishing the Medicaid program into law in 1965 , solving the problem of the uninsured through government intervention seemed infinitely possible. Jointly funded by state and federal governments, Medicaid was designed to provide health care benefits to low income populations, primarily children and women of childbearing age. Although Medicaid was expected to be a temporary program that would soon be replaced by some form of national health insurance, Medicaid spending and enrollment only continued to grow. Thirty years after its introduction, not only cloes Medicaid still exist, but in 1995 alone, the program spent $\$ 152$ billion on health care services for approximately 36 million people. ${ }^{1}$ Children, who comprise nearly half of these 36 million recipients, depend on Medicaid's Early and Periodic Screening, Diagnosis and Treatment (EPSDT) services for preventive care such as immunizations, vision and hearing screenings, and other cost effective treatments that promote hillhy development 


\section{Spiraling costs}

\section{and the failure}

of Medicaid to

provide its

beneficiaries

with reliable

access to

physicians and

health services

have caused

states to

experiment

with managed

care as a

means to

control costs

and improve

access. and reduce future health problems. Clearly, children have the most to gain from improvements to the Medicaid program, but they also have the most to lose if this health delivery system continues to experience problems with health care quality and access.

Spiraling costs and the failure of Medicaid to provide its beneficiaries with reliable access to physicians and health services have caused states to experiment with managed care as a means to control costs and improve access. This papers endeavors to analyze the problems that drove states to pursue managed care, reviews the successes and failures of Medicaid managed care, and proposes recommendations that will assist in reforming Medicaic managed care into a health delivery system that will both control health care costs and improve access to preventive care for children.

\section{Medicaid Payment History}

Until recently, physicians who provicled treatment to Medicaid recipients were paid using the fee-for-service system, a payment method which reimburses doctors for each test, procedure, and office visit, based on a predetermined fee schedule. Critics of the fee-for-service system charge that since payment is based on volume, rather than on the improved health status of patients, it encourages unnecessary tests, office visits, and hospital stays. In addition, there is little incentive for physicians to provide preventive care such as immunizations and other health screenings, as this care will likely reduce future illnesses for their patients and their own future incomes.
Since the Medicaid fee schedule reimburses physicians at a lower rate than the private sector, reduced fee-for-service has had the unintended consequence of decreasing access to physicians for the Medicaid population. When Medicaid's reimbursement rates failed to keep up with the increased costs of providing medical care, numerous physicians refused to accept Medicaid patients. This reduction of physician accessibility has contributed to the problem of Medicaid patients turning to the emergency room for health services. This substitution is problematic for both the health care industry and the Medicaid population, as emergency room care is exceedingly costly and preventive care is almost nonexistent.

In contrast to fee-for-service, most managed care plans use capitation as a payment mechanism. Under this system, physicians are paid a fixed amount of money per member, per month to cover medical care. The payment remains the same, regardless of the number of times a patient uses health services, or even if no medical care is provided at all. The benefit of capitation as a payment mechanism is the incentive it provides for physicians to emphasize preventive care. Unlike fee-for-service plans, which reward doctors for costly procedures, capitation encourages physicians to schedule periodic check-ups, vision and hearing screenings, immunizations, and other services that will prevent costly health problems. Thus, physicians benefit financially from healthy patients, who allow them to keep larger portions of capitation payments as profit. 


\section{Populations Served}

Medicaid recipients include children, adult caregivers (primarily women of childbearing age), the elderly, and the blind and disabled. According to 1995 statistics from the Health Care Financing Administration (HCFA), the Medicaid population broke down by category as follows:

- 18.7 million children;

- 7.6 million adults who care for these children;

- 4.4 million elderly; and

- 5.9 million blind and disabled.

(Some beneficiaries are included in more than one category).

While the other aforementioned groups are certainly affected by Medicaid policy, children are clearly the greatest stakeholders, the population most impacted by the services (or lack thereof) of the Medicaid program. One out of every four children in the nation relies on Medicaid for health care services ${ }^{2}$, and Medicaid covers one-third of all babies born in the United States. 3 The Medicaid program is one of the largest and most significant providers of health care for our children, simply because of the sheer number of children that depend on Medicaid for their medical needs. Thus, improving the scope and quality of health care services administered through the Medicaid program would result in improved health outcomes for some of the most vulnerable children in the nation.

\section{Health Benefits}

Arguably, the most crucial Medicaid services for children are those that focus on prevention. Early and Periodic Screening, Diagnosis and Treatment (EPSDT) services, a component of Medicaid, was designed to ensure that preventive health services would be available for low income children under the age of twenty-one. The basic preventive care mandated by EPSDT includes medical screenings, vision, dental, and hearing services. Screening services entail comprehensive physical and mental health testing, a developmental history, a comprehensive physical exam, immunizations, laboratory tests, and health education. ${ }^{4}$ In addition to funding health services for all covered children, EPSDT has become a major funding source for children with special needs who require services such as hearing aids, eyeglasses, respiratory care, and mental health care. 5

The importance of children's access to preventive health care services is twofold. First, children have unique health needs. Physiological, cognitive, and emotional development occurs most swiftly between infancy and adolescence. This rapid growth causes children to be extremely vulnerable to factors in their physical and social environments. However, most infectious diseases can be avoided if children receive preventive care, screenings, and immunizations at the appropriate times. ${ }^{6}$ Second, children who are high utilizers of preventive health care services are less likely to suffer from adverse health outcomes later in life. 7 Hence, preventive care both improves the health and well being of children, and is also cost-effective, as future
Thus,

improving the

scope and

quality of

health care

services

administered

through the

Medicaid

program would

result in

improved

health

outcomes for

some of the

most

vulnerable

children in the

nation. 
Without

making any

other changes

to the health

care system,

simply

enrolling all

eligible

children in

Medicaid

would improve

the state of

affairs for our

nation's

uninsured

children. medical expenses are likely to be recluced.

Access to preventive services and coordinated health care delivery are particularly crucial for children who rely on Medicaid, as they are more likely to suffer from more chronic conditions and have more disabilities than privately insured children. In fact, state data suggest the prevalence rates of chronic illness for children on Medicaid may exceed 20 percent. ${ }^{8}$ In addition, when hospitalized, Medicaid-covered children tend to require more care and remain in the hospital longer than other children do.?

Certainly, the preventive services provided by EPSDT are crucial to ensure good health for children. Unfortunately, most states are not meeting Medicaid's mandate that all eligible children receive preventive care through the EPSD $T$ program. Of the 22.9 million children that were eligible for EPSDT services in 1996, only 37 percent received a medical screening, 21 percent received a dental screen, 15 percent received a vision screen, and 13 percent received a hearing screen. ${ }^{10}$ Clearly, EPSDT has not lived up to its promise of comprehensive health care and early screening for eligible children.

\section{Enrollment and Cost}

Almost immediately following the establishment of the Medicaid program, enrollment exceeded estimates. The number of people receiving Medicaid benefits continued to climb, and did not begin : to level off until 1992. Corresponding with increased enrollment, the cost of providing Medicaid benefits also rose steadily. Between the years of 1988 and 1992, Medicaid expenditures grew on average by 22.4 percent per year, increasing from $\$ 53.5$ billion in 1988 to $\$ 119.9$ billion in $1992 .{ }^{11}$

Following years of intensive expenditure growth, the Medicaid annual growth rate began to slow in 1992. From 1992 to 1995, Medicaid spending grew on average by 9.5 percent per year, down from 22.4 percent per year during the previous four years. ${ }^{12}$ Medicaid enrollment growth also began to slow, increasing by only 1.8 percent in 1995.13 Medicaid spending per enrollee also fell during the same time period possibly as a result of managed care.

Despite increases in the overall number of beneficiaries, the Medicaid program is failing to reach all eligible children. In fact, an estimated 4.7 million eligible children are currently not enrolled in Medicaid. ${ }^{14}$ Enrollment barriers and lack of awareness of the program are cited as the primary reasons for failure to enroll eligible children. Without making any other changes to the health care system, simply enrolling all eligible children in Medicaid would improve the state of affairs for our nation's uninsured children. This seemingly simple task would reduce the number of uninsured children by nearly half. 15

\section{Moving to Managed Care}

Escalating costs, poor access to physicians, and lack of emphasis on preventive care have all contributed to Medicaid's shift from fee-for-service to the use of managed care. Initial managed. care enrollment efforts have focused on women of childbearing age and children, leaving the elderly and disabled, 
populations that have higher utilization rates and spending per enrollee, in feefor-service plans. In 1991, approximately 9.53 percent of the Medicaid population was enrolled in some type of managed care plan. ${ }^{16}$ Changes in federal regulations provided states with greater freedom in expanding the use of managed care, and as a result, enrollment grew to 40.1 percent in 1996.17

Children have always been enrolled in Medicaid managed care at a higher rate than adults. This trend may be attributed to the fact that children make up a larger percentage of Medicaid recipients, and because the health problems of most children tend to be less complex than those of adults, particularly those of the elderly and disabled. Women of childbearing age have also been enrolled in managed care in significant numbers.

While these populations make up the majority of Medicaid recipients, the choice to make young women and children priorities in managed care enrollment may have been shortsighted. The effect on cost containment will likely be limited, as women of childbearing age and children make up 85 to 90 percent of Medicaid managed care enrollees, but together only account for 26 percent of Medicaid program costs. ${ }^{18}$ The populations with the highest spending per enrollee, the elderly and the disabled, predominantly remain in fee-for-service plans.

\section{Advantages of Medicaid Managed Care for Children}

Reduced health care costs is one of the greatest advantages of managed care, as the government, managed care plans, health care providers, and children all benefit from decreased spending. Both state and federal governments are eager to reduce their budgets, and limiting Medicaid spending growth plays a key role in this effort. When capitation is used as a method of payment, physicians and managed care plans also benefit from decreased health care expenditures, as they are able to keep a greater percentage of the capitation payment as profit.

Most importantly, children benefit when health care dollars are used efficiently and costs are reduced. If managed care plans are able to make a profit while serving the Medicaid population, then other plans are more likely to enter the Medicaid market. The resulting competition would give states the leverage to demand more health care services for Medicaid beneficiaries, and turn away managed care providers with questionable quality of care records.

The estimated 4.7 million eligible, yet uncovered children would also benefit from Medicaid cost savings. States could use these savings to implement campaigns to reach eligible children, including public service announcements, visits to local community centers and public schools, and a greater availability of information in Spanish and other languages. Managed care companies might also be willing to participate in this effort, as it would offer the opportunity to enroll more members in their plans.

Furthermore, children benefit from managed care because of its emphasis on preventive care and coordinated health care delivery. Most managed care plans assign patients to a specific pri-
Furthermore, children

benefit from

managed care

because of its

emphasis on

preventive care

and

coordinated

health care

delivery. 
...some trends

that have

emerged

suggest that

managed care

plans have

made progress

in coordinating

health care

delivery for

children. mary care physician (PCP), and this physician must be utilized for most health services. Referrals to specialists or other providers may be granted, but only after consultation with the PCP. Ideally, this arrangement results in a primary care physician seeing a child on a regular basis, thereby gaining an understanding of the child's medical history. When a physician has regular contact with the same children, it becomes easier to monitor their well being, administer appropriate immunizations and screenings, and serve other health care needs.

\section{Disadvantages of Medicaid Managed Care for Children}

One of the biggest disadvantages of managed care, versus fee-for-service plans, is the disincentive to enroll chronically ill or disabled children. Arguably, these are the children who would benefit most from the coordinated health care delivery that managed care organizations claim to offer. However, since children with special needs require more frequent and costly medical services, spending per enrollee tends to be much higher for this group than other children covered by Medicaid. Physicians and managed care plans are both likely to lose money by serving the chronically ill and disabled, as their health care costs will likely exceed capitation payments. Managed care companies' inclination to avoid children with special needs is evidenced by the intentional limitation of their enrollment efforts to healthy children and young women.

The incentive to provide preventive care as a method of reducing future costs is also lessened when providing man- aged care coverage to Medicaid recipients. As opposed to their privately insured counterparts, children relying on Medicaid typically remain eligible for Medicaid benefits for only short periods of time. Due to the sporadic nature of Medicaid enrollment, children are likely to receive benefits for a few months, lose coverage, and later regain Medicaidsponsored health care benefits. Managed care companies simply do not have the incentive to provide preventive care to children to reduce future costs, as most Medicaid recipients will not be covered for more than a few years. By the time any serious health problems are detected, it is likely that the child will no longer be enrolled in Medicaid.

\section{Mixed Results with Medicaid Managed Care}

Since a variety of managed care approaches have been used to serve the Medicaid population, drawing definitive conclusions about the effect of managed care on quality and access to care is difficult. However, some trends that have emerged suggest that managed care plans have made progress in coordinating health care delivery for children.

For instance, Medicaid managed care has been successful in reducing the use of emergency rooms for non-urgent care. The Kaiser Commission on the Future of Medicaid reported that in an evaluation of twelve studies, nine cases reflected a decrease in emergency room visits among children. In some of those cases, the reduction in visits totaled as much as 27 to 37 percent. ${ }^{19}$ Denial of emergency care remained at a mere 3 percent, discounting the theory that children who 
truly needed emergency services were being denied care. ${ }^{20}$

Despite this promising reduction in emergency room visits, a corresponding increase in visits to primary care physicians has not materialized. Rigorous analysis of twelve Medicaid managed care programs, by Robert Hurley and others, found that three programs experienced an increase in physician visits, five programs experienced a decrease in visits, and four programs reported mixed, unchanged, or unknown results. ${ }^{21}$ While additional research is still necessary, these studies suggest that at best, Medicaid managed care has not improved access to primary care physicians, and at worst, may have actually reduced access to PCPs when compared with fee-for-service plans. As previously discussed, significant improvements to managed care are still necessary to ensure that the program fulfills the health care needs of our nation's most vulnerable children.

\section{Future Implications}

In the future, Medicaid recipients are even more likely to be enrolled in managed care. The federal government has reduced the number of mandates and requirements pertaining to Medicaid, allowing individual states to make the majority of decisions on how to provide health care benefits to their low income populations. States used the early $1990 \mathrm{~s}$ to gradually enroll portions of their Medicaid population into managed care, and trends suggest that mandatory enrollment for the Medicaid population will become even more prevalent.
The political climate also supports the assumption that Medicaid managed care will become more widespread in the future. The Medicaid program has been vilified by both major political parties as a fraudulent, wasteful program that siphons limited resources away from other important government efforts. Despite the fact that Medicaid growth has slowed in recent years, it remains a costly program, and managed care is seen as a way to limit Medicaid expenditures.

Although managed care is one of the least popular insurance options, it will likely become an even more prevalent program for the Medicaid population for another reason. It is important to remember that Medicaid provides coverage for two of the politically weakest populations in the United States - children and the poor. Groups that do not vote with regularity, contribute to political campaigns, or in other ways wield power within Congress, state legislatures, or the federal and state level executive branches, traditionally do not fair well during the budget process. Although there is a commitment in the U.S. to provide a minimum level of medical care for the nation's poor, efforts to expand the eligible population, or otherwise improve health care delivery, are unlikely to succeed unless they can be implemented without substantially increasing expenditures.

Since concerns regarding general managed care programs are not restricted to Medicaid recipients, extending also to certain politically powerful populations, government regulation of managed care is likely to increase. Several bills pertaining to managed care regula-
It is important

to remember

that Medicaid

provides

coverage for

two of the

politically

weakest

populations in

the United

States -

children and

the poor. 
Rather than

expending

energy

formulating

other unrealistic

alternatives,

children will be

best served by

efforts aimed at

improving the

existing

program. tion have been introduced in both the House and Senate of the 106th Congress. In addition, President Clinton, as well as Republican and Democratic members of Congress, have indicated that passage of legislation to reform managed care is a priority.

While government regulation of managed care is appropriate and necessary, additional rules and requirements will make reducing expenditures even more challenging. It is highly unlikely that enough managed care plans will be attracted to the Medicaid market if capitation rates continue to be lowered while minimum standards are increased. Without enough competitors, states will lose their negotiating leverage. As a result, it will be more difficult to demand low capitation rates or turn away managed care providers with questionable quality of care records.

\section{Recommendations}

Current trends suggest that Medicaid managed care is here to stay. Rather than expending energy formulating other unrealistic alternatives, children will be best served by efforts aimed at improving the existing program. Improving the accessibility of preventive care, expanding outreach services, and developing information systems are all essential components in the effort to improve health care delivery for Medicaid children.

\section{Develop an incentive system to} encourage preventive bealth care for children.

Any effort to reform Medicaid should include steps to improve access to preventive care for children. Periodic screenings and other forms of preventive care promote healthy development, and also reduce the chances of adverse health outcomes later in life. Preventive care improves the health and well being of children, and is also cost effective, as future medical expenses are likely to be reduced.

Managed care is built on the foundation that capitation rates will encourage physicians to provide relatively low cost preventive care to their patients. This basic assumption is not a sufficient incentive to encourage preventive care when dealing with the Medicaid population, as children are typically enrolled briefly and are not likely to be covered by Medicaid when any serious health problems emerge.

Since the sporadic nature of Medicaid enrollment reduces the incentive to provide preventive care to children, states should consider developing alternative incentive systems to encourage this care. Providing managed care companies with an opportunity to share any realized cost savings, or including withholds in the payment structure to health plans, are two potential incentive structures.

The sharing of cost savings would provide managed care companies with an incentive to improve preventive care for children. If a state experiences lower Medicaid expenditures following the expansion of managed care, a portion of these savings should be passed on to the managed care company that has delivered the best health care to children. For example, the plan with the highest immunization rates, or the largest increase in the number of eligible children receiv- 
ing EPSDT services, could be rewarded with a portion of these savings.

Withholds could also be used as an incentive technique. States would continue to make the standard monthly capitation payments, but could retain a portion of the payment until the end of the year. In order to receive the withhold, managed care plans would have to meet several predetermined goals, such as a reduction in the number of children experiencing frequent and severe asthma attacks, a decrease in emergency room visits, or an increase in the number of children visiting a primary care physician.

\section{Extensive outreach services should be}

\section{implemented in order to ensure that}

families are aware of the accessibility and availability of services for

\section{cbildren.}

High quality health care services are useless if they are inaccessible, or if the eligible population is not aware of their availability. Unfortunately, the Medicaid program has not done a good job of advertising its services, and improving outreach will require a two-pronged approach. First, states must improve communication with the families of children currently enrolled in Medicaid. Second, states must reach out to the children who meet eligibility requirements, but are not currently enrolled in Medicaid.

The families of children currently enrolled in Medicaid need to be aware of the location of health care providers and the scope of services available to them. Convenient locations, expanded hours of operation, and the availability of reli- able transportation are essential to facilitate accessibility, and to ensure that Medicaid recipients will be able to obtain proper medical care. Providing toll free telephone hotlines, staffed by personnel qualified to answer medical questions and provide information on area services, is another way to inform Medicaid recipients and encourage the use of appropriate medical care.

Additional and aggressive outreach should also be directed at the 4.7 million children eligible for, but not receiving, Medicaid benefits. States and managed care companies should hire personnel to visit low income communities and reach out to children and their families. Fluency in a variety of languages, an appreciation of the many difficulties that low income families face, and an understanding of the complex Medicaid regulations and requirements will be important and necessary skills for outreach personnel. The difficulty of reaching these children should not be underestimated, but neither should the urgency. Despite the fact that these children meet eligibility requirements, they are not receiving the medical services necessary to protect them from infectious diseases, promote healthy development, and avoid future health problems.

\section{Government and managed care bealtb}

\section{plans need to develop comprebensive}

\section{information systems.}

Reliable information systems are a necessary component of any health care delivery system, and Medicaid managed care is no exception. The use of information systems would improve administrative efficiency, and would serve a variety of other crucial functions. When used ef-
The difficulty of

reaching these

children should

not be

underestimated,

but neither

should the

urgency. 
Despite its

deficiencies,

however,

Medicaid has

unquestionably

improved the

overall health

status of the

nation's poor. fectively, information systems can, assist in the promotion of preventive care, $\mathrm{fa}$ cilitate outreach to the families of Medicaid children, and measure the quality of care.

In order to provide the best care, medical staff must have as much information as possible about a child's medical history. The sporadic eligibility of children for Medicaid services, and the use of multiple medical caregivers, including emergency room staff, makes record keeping extraordinarily difficult. Thus, the development of a computerized medical record for Medicaid recipients would greatly assist in tracking patient history. The ability to access a child's medical information in a clear and legible format would allow clinical staff to easily determine appropriate service needs, such as when to schedule a child for a physical or immunization. Computerized records would also reduce the number of duplicative tests and procedures resulting from unavailable patient records.

Information systems also play an important outreach role to the families of Medicaid children. For example, patient data could be manipulated to generate a mailing list of all children with asthma, and newsletters and other educational materials could be mailed to these households. Similarly, mailing labels could be created to send post cards reminding families to schedule a visit when children need a vision screening or other medical service. Information systems provide a tremendous opportunity to improve the link between primary care providers and the children whom they serve.
Finally, information systems are a necessity in order to measure the quality of Medicaid managed care. Data collection allows states to review utilization patterns, health outcomes, and patient satisfaction. The National Committee for Quality Assurance (NCQA), an independent group formed to promote standards, review procedures, and performance measures for managed care organizations, provides a data reporting standard known as the Healthplan Employer Data and Information Set (HEDIS). HEDIS establishes performance criteria in more than sixty categories and these performance measures provide a baseline to evaluate managed care organizations. ${ }^{22}$ If states do not have effective information systems to collect data, they will be unable to compare the performance of their Medicaid managed care plans versus the HEDIS baseline. Consequently, states will need comprehensive information systems in order to determine whether children are receiving appropriate medical care.

\section{Conclusion}

Since its inception in 1965, the Medicaid program has provided health services to hundreds of millions of individuals, the majority of whom have been children. Undoubtedly, the Medicaid program has many shortcomings, and poor access to preventive care for children is a notable example. Despite its deficiencies, however, Medicaid has unquestionably improved the overall health status of the nation's poor.

The 1990s have been a turbulent decade for Medicaid, as the federal government has turned much of the control 
of the program over to the states. Most states have used this opportunity to increase the use of managed care as a method of delivering health services to Medicaid beneficiaries, directing expansion efforts at young women and children.

Rather than efficiently managing care and improving health outcomes as a means to achieve savings, the current focus of many Medicaid managed care plans is on cutting expenditures as a method to reduce costs. This focus threatens to jeopardize the well being of our nation's children, thus, the government must ensure that improvements in health care quality and access are also prioritized. Governmental failure to advocate for improvements in these areas will be viewed as an endorsement of sacrificing care for reduced costs.

Children have experienced mixed results under Medicaid managed care. While there appears to have been a reduction in the use of emergency rooms for non-urgent care, Medicaid managed care has failed to produce a corresponding increase in visits to primary care physicians. The lack of financial incentives for physicians and managed care plans has prevented an increase in preventive care and coordinated health care delivery for children.

The transition of the Medicaid population from fee-for-service to managed care presents both challenges and opportunities in the effort to provide high quality health care services to children. Developing an incentive system to promote preventive care, implementing extensive outreach services, and investing in information systems will assist in improving health care outcomes for children relying on Medicaid.

Expanding the use of managed care will not cure all of the ailments of the Medicaid program. It will not result in medical coverage for all poor children, it will not end problems with access to physicians, and it will not completely halt rising health care costs. However, refraining from improving the existing managed care framework merely because Medicaid managed care is not the ultimate solution is a severe disservice to children. The children who currently rely on Medicaid do not have time to wait for the creation of a new health care delivery system, or the passage of universal health care legislation. Although these policy options may be our ultimate goals, they are not realistic short-term options.

In contrast, improving existing managed care is a viable and effective option. Before us is an incredible opportunity to change the way health care is delivered to Medicaid recipients. Instead of passively reimbursing physicians for providing sporadic medical care, managed care has the potential to evolve into a proactive system that rewards doctors for keeping children healthy. The quest to provide health care coverage for all children does not end with Medicaid managed care. However, as we work toward that difficult and sometimes seemingly unattainable goal, surely improving our current system to benefit children's health is a worthy pursuit.
Before us is an incredible opportunity to change the way health

care is

delivered to

Medicaid

recipients. 


\section{Notes}

tI would like to thank the entire staff of Policy Perspectives, who generously committed their time and energy to make the publication of this journal possible. In particular, I would like to thank the following people: Editor in Chief Meredith McWade, for her insight, patience, and most importantly, her friendship; Associate Editor, Cindy Cortinas Uviedo, for her diligence and research; and Professor Jill Kasle, who constantly challenged me and pushed me to do my best, first in the classroom and later as an author. Finally, warmest thanks to Danielle Noll, Charlie Pryde, and Sandy Ulsh, who kindly read my article, offered suggestions, and graciously shared their extensive knowledge of health care with me.

1 Lisa W. Deal and Patricia H. Shiono, "Medicaid Managed Care and Children: An Overview," Cbildren and Managed Health Care, (Summer/Fall 1998): 95.

2 National Association of Children's Hospitals, "Medicaid: Nation's Health Care Safety Net for Children," March 1997; available from http://www.kidscampaign.org/Hot/Early/medicai d.htm; INTERNET.

3 Health Care Financing Administration, "The Medicaid Program," 11 September 1996; available from

http://www.hcfa,gov/medicaid/modsta95.htm; INTERNET.

Deal and Shiono, 95 .

5 Ibid.

${ }^{6}$ Peter G. Szilagyi, "Managed Care for Children: Effect on Access to Care and Utilization of Health Services," Children and Managed Health Care, Summer/Fall 1998, 40.

7 Ibid.

${ }^{8}$ National Association of Children's Hospitals, "Medicaid: Nation's Health Care Safety Net for Children."

9 Ibid.
10 Kristi Olson, Jane Perkins, and Tonya Pate, "Children's Health Under Medicaid: A National Review of Early and Periodic Screening, Diagnosis and Treatment," National Health Law Program, August 1998; available from http://nhelp.org/pubs/child1998healthxsum.html ; INTERNET.

${ }^{11}$ Stuart Altman, Uwe Reinhardt, and Alexandra Shields, The Future U.S. Healtbcare System: Who Will Care for the Poor and Uninsured?, (Chicago, IL: Health Administration Press, 1998), 67-74.

12 Ibid.

13 Ibid.

14 Kaiser Family Foundation, "Medicaid's Role for Children," November 1997; available from http://www.kff.org/; INTERNET.

15 Kaiser Family Foundation, "The Uninsured and Their Access to Health Care," October 1998; available from http://www.kff.org/; INTERNET.

16 Health Care Financing Administration, "National Summary of Medicaid Managed Care Program and Enrollment," 30 June 1996; available from

http://www.hcfa.gov/medicaid/trends1.htm; INTERNET.

17 Ibid.

18 Deal and Shiono, 93.

19 Diane Rowland, Sara Rosenbaum, Lois Simon, and Elizabeth Chait, Medicaid and Managed Care: Lessons from the Literature, (Washington, D.C.: The Henry J. Kaiser Family Foundation, 1995), 13-22.

\footnotetext{
20 Ibid.

21 Ibid.

22 Peter R. Kongstvedt, The Managed Health Care Handbook, (Gaithersburg, MD: Aspen Publishers, Inc., 1996), 466.
} 


\section{BIBLIOGRAPHY}

Altman, Stuart, Uwe Reinhardt, and Alexandra Shields. The Future U.S. Healthcare System: Who Will

Care for the Poor and Uninsured? Chicago, IL; Health Administration Press, 1998.

Deal, Lisa W. and Patricia H. Shiono, "Medicaid Managed Care and Children: An Overview." Children and Managed Health Care. Summer/Fall 1998.

Health Care Financing Administration. "The Medicaid Program." (11 September 1996). Available from http://www.hcfa.gov/medicaid/modsta95.ht m; INTERNET.

"National Summary of Medicaid Managed Care Programs and Enrollment." (30 June 1996). Available from http://www.hcfa.gov/medicaid/trends1.htm; INTERNET.

Kaiser Family Foundation. "Medicaid's Role for Children." (November 1997). Available from http://www.kff.org/; INTERNET.

"The Uninsured and Their Access to Health Care." (October 1998). Available from http://www.kff.org/; INTERNET.
Peter R. Kongstvedt. The Managed Health Care Handbook. Gaithersburg, MD: Aspen Publishers, Inc., 1996.

National Association of Children's Hospitals. "Medicaid: Nation's Health Care Safety Net for Children." (March 1997). Available from http://www.kidscampaign.org/Hot/Early/me dicaid.htm; INTERNET.

Olson, Kristi, Jane Perkins, and Tonya Pate. "Children's Health Under Medicaid: A National Review of

Early and Periodic Screening, Diagnosis and Treatment." National Health Law Program. (August 1998), Available from http://nhelp.org/pubs/child1998healthxsum. html; INTERNET.

Rowland, Diane, Sara Rosenbaum, Lois Simon, and Elizabeth Chait. Medicaid and Managed Care: Lessons from the Literature. Washington, D.C.: The Henry J. Kaiser Family Foundation, 1995.

Peter G. Szilagyi, "Managed Care for Children: Effect on Access to Care and Utilization of Health Services." Children and Managed Health Care. Summer/Fall 1998. 
